\title{
Pleistozäne Dünensande in der Tschechoslowakischen Sozialistischen Republik
}

\author{
Von J. PeLišEk, Brünn
}

Zusammenfassung: Die Dünensande auf dem Gebiete der ČSSR sind in verschieden großen Inseln, im Böhmischen Massiv und im Karpathenbereiche, in Seehöhen von 100-400 m verbreitet. Ihre Mächtigkeit beträgt meistens $2-10 \mathrm{~m}$, stelienweise bis $30 \mathrm{~m}$. Morphologisch betrachtet, bilden sie verschiedenartige Hügel und Dünen. Der Größe ihrer Körner nach bilden sie 3 Varietäten, wobei die Dünensande mit einem Korndurchmesser von $0,25-0,50 \mathrm{~mm}$ am meisten verbreitet sind (50-70\%). In petrographischer Hinsicht überwiegt der Quarzgehalt; im Böhmischen Massiv sind sie karbonatfrei, im Karpathengebiete jedoch karbonathaltig $\left(10-25 \% \mathrm{CaCO}_{3}\right)$. Die Entstehung der Dünensande erfolgte hauptsächlich durch Auswehung aus den Pleistozänterrassen und aus den verwitterten Gesteinen der tertiären Sedimente und aus Sandsteinen der oberen Kreideformation. Sie sind von verschiedenem pleistozänen Alter (überwiegend Riß und Würm). Sie wurden überwiegend durch Winde einer Stärke von 3-9 m transportiert.

$\mathrm{R}$ é $\mathrm{sumé}$ : Les sables éoliens du pleistocène de la Tchécoslovaquie. On trouve des sables éoliens dans la région de la Tchécoslovaquie en forme d'îles d'étendue différente dans le massif de Bohême et dans la région carpathique à une hauteur de $100-400 \mathrm{~m}$. Leur puissance est en grande partie de 2-10 mètres, par endroits même de $30 \mathrm{~m}$. Au point de vue morphologique ils forment des collines en formes différentes, des dunes et même des formes dites de barchan, tandis que de point de vue granulométrique on peut distingueur 3 variétés, dont la plus répandue forment les sables éoliens, composés dans la plupart $(50-70 \%)$ des grains de moyen diamètre de 0,25 a $0,50 \mathrm{~mm}$. Le degré d'assortiment même que le degré de l'arrondissage eux aussi sont très bien deve'oppés. Au point de vue pétrographique les sables se composent en majeure partie de quartz. Dans le massif de Bohême les sables éoliens ne contiennent d'aucuns carbonates, dans la région carpathique par contre leur contenu en $\mathrm{CaCO}_{3}$ égale 10 à $25 \%$. Les sables éoliens ont été formés surtout par l'activité des vents qui les ont emportés de terrasses pleistocènes et de masses de roches décomposées de sédiments appartenants à la formation tertiaire et de grès crétacés superficiels. Ils sont d'âge différent de pleistocène et se formèrent par la plupart pendant le Riss et le Würm de la période glaciale. Pendant le Holocène ils ont été par endroits déplacé et cela par des vents d'une vitesse de 3 à $9 \mathrm{~m}$. Les gisements de sables éoliens avec les couches inférieurers sur les terrasses sabloneuses et de pierraille Würm sous la plaine alluviale des rivières (l'Elbe, la March, la Thaya, le Danube etc), de même que leur couverture partielle par de sédiments fluviaux témoigne d'un abaissement continuel de ces territoires dans la région de l'Europe Centrale.

$\mathrm{Summary}$ : The pleistocene aeolian sands of Czechoslovakia. The aeolian sands on the territory of Czechoslovakia are spread as islands of different dimensions in the so-called massiv of Bohemia and in the Carpathian region in the altitude of $100-400 \mathrm{~m}$ above the sea-leve'. For the most part they are $2-10 \mathrm{~m}$ thick in places till $30 \mathrm{~m}$. Morpho!ogically they form little hills of different shapes, sand dunes as well as the so-called barchan forms. Granulometrically, there may be distinguished 3 varieties, the most frequent of which are the aeolian sands consisting for the most part $(50-70 \%)$ of grains of $0.25-0.50 \mathrm{~mm}$ size. The level of assortment and of the rounding off of the sand grains are advanced too. Petrographically these sands consist mostly of quartz. In the massif of Bohemia the aeolian sands don't contain any carbonates, whereas in the Carpathian region they have a contenance of about $10-25 \% \mathrm{CaCO}_{3}$. These sands were developed mainly by blowing out from the Pleistocene terraces and weathered Tertiary deposits and from the upper Cretaceous sandstones. They are of different Pleistocene age and formed during the Riss and Würm of the Glacial period. As a rule they were disslaced in Holocene time by the winds of $3-9 \mathrm{~m}$ intensity. The deposits of aeolian sands with the underlving lavers on the sandv-gravelly Würm terraces, under the alluvial river-plains (Elbe, March, Thaya, Danube etc.), and their partial covering by the Holocene sediments bear witness of the lasting sinking of these territories in the region of Central Europe.

Ảolische Pleistozän-Sedimente im Bereiche der ČSSR können nach ihrer KorngrößenZusammensetzung grob in zwei Grundgruopen eingeteilt werden: die feinkörnigeren Lösse und die mehr grobkörnigen Sande. Für die Lösse ist der hohe Gehalt an Mineralkörnern von einem Durchmesser von $0,01-0,05 \mathrm{~mm}$ (der sog. Staub), dessen Gehalt 45-55\% erreicht, besonders charakteristisch. Die Dünensande enthalten dagegen einen hohen An- 
teil der gröberen Kornfraktion, des sog. Sandes, dessen Korndurchmesser zwischen 0,1-2,0 mm schwankt und mit 65-95\% mengenmäßig vertreten ist.

Die Dünensande sind in der ČSSR in den Niederungslagen verbreitet, wo sie entweder größere, zusammenhängende Flächen mit mäßig gewelltem Relief oder Gruppen von verschieden großen Dünen bilden. Dünensandbedeckungen sind sowohl im Bereiche des Böhmischen Massivs als auch im Karpathengebiet verbreitet.

Untersuchungsmethode

Die Untersuchung der Dünensande wurde im Terrain sowie im Laboratorium durchgeführt. In den Laboratorien wurde die Korngrößenzusammensetzung bestimmt und die Sandfraktion mittels Bodensieben in 6 Gruppen detailliert aufgeteilt. Auch wurde die Abrundung der Körner bzw. das gegenseitige Verhältnis der scharfkantigen Körner zu den abgerundeten festgestellt. Der Chemismus wurde in dem mittels $20 \%$ iger, heißer Salzsäure gewonnenen Auszug, zwecks Feststellung der löslicher, gewöhnlichen chemischen Bestandteile, ermittelt.

Für die Dünensande ist die Menge der Körner vom 0,1-0,75 mm bezeichnend. Zahlreiche ausführliche Korngrößen-Analysen der Dünensande von allen Gebieten der ČSSR ermöglichten es, die 3 Hauptvarietäten der Körnung je nach dem Ubergewicht gewisser Korngrößen festzustellen. Es sind dies folgende Körnungsvarietäten:

a) Korngrößenvarietät I mit stark überwiegendem Anteil der Sandkörner mit einem Durchmesser von $0,1-0,25 \mathrm{~mm}$,

b) Korngrößenvarietät II mit einem starken Übergewicht der Sandkörner mit einem Durchmesser von $0,25-0,50 \mathrm{~mm}$,

c) Korngrößenvarietät III mit Übergewicht der Sandkörner mit einem Durchmesser von $0,50-0,75 \mathrm{~mm}$.

Die Dünensande im Bereiche des Böhmischen Massivs

Die Dünensande sind im Bereiche des Böhmischen Massivs hauptsächlich im Bereiche des zentralen Elberaums, in Ost- und Südböhmen, im Bereiche des nordmährischen Beckens, auf dem Alluvialplateau des unteren Laufes des Dyje (Thaya)-Flusses und in der schlesischen Niederung verbreitet. Sie bilden daselbst Bedeckungen von verschieden starker Mächtigkeit, jedoch durchwegs in kleineren Seehöhen. Im Gebiet des zentralen Elberaums sind sie in den Seehöhen von 200-250 m. in Ostböhmen 250 bis $265 \mathrm{~m}$, in Südböhmen 410-430 m, im Bzenec-Hodonín-Gebiete (Bisenz-Göding in Südmähren) in den Seehöhen von $170-210 \mathrm{~m}$, im Alluvialplateau des nordmährischen Beckens in den Seehöhen von $156-188 \mathrm{~m}$, im nordmährischen Becken ungefähr in $200 \mathrm{~m}$, in der Alluvialebene des Thavabeckens in den Seehöhen von $168-170 \mathrm{~m}$, in der schlesischen Niederung in den Seehöhen von $230-250 \mathrm{~m}$ verbreitet. Es befinden sich also die Dünensande in der Hauptsache in Seehöhen von 156 bis $260 \mathrm{~m}$, somit durchwegs in den Niederungslagen, und nur im Südböhmen erreichen sie im Hügellande eine Seehöhe von $410-430 \mathrm{~m}$.

Der Großteil dieser Sande erscheint in der Form von flacheren Hügeln, der kleinere Teil weist sodann flachere, auf der Windseite gelegene, gegen W bis NW orientierte, sowie steilere, windgeschützte, gegen $\mathrm{O}$ und $\mathrm{SO}$ exponierte Abhänge auf. Die relative Höhe der Dünensand-Aufwehungen ist verschieden und schwankt meist zwischen 2 und $6 \mathrm{~m}$, jedenfalls weniger als $10 \mathrm{~m}$. Die Unterlage der Dünensande bilden in der Hauptsache die sandig-schotterigen oder schotterig-sandigen Terrassen von verschiedenem Alter, Kristallin, Paleozoikum, obere Kreideformation sowie die Neogensedimente. In den Gebieten der alluvialen Flußebenen wurden die Dünensande in einer Tiefe von $1-3 \mathrm{~m}$ unterhalb der Oberfläche der Alluvial-Sedimente abgelagert, so daß nur die oberen Teile der Dünensande die umliegende alluviale Flußaue überragen. 
Tabelle 1

Durchschnittliche Zusammensetzung der Dünensande im Gebiete der ČSSR.

I, II, III bezeichnen verschiedene Varietäten der Korngrößenverteilung.

\begin{tabular}{c|c|c|c|c|c|c}
\hline \multirow{2}{*}{ Korngröße $\phi \mathrm{mm}$} & \multicolumn{3}{|c|}{ Gebiet des Böhmischen Massivs } & \multicolumn{3}{c}{ Karpatengebiet } \\
\cline { 2 - 7 }$<0,01$ & I & II & III & I & II & III \\
$0,01-0,05$ & $2-8 \%$ & $2-8 \%$ & $1-4 \%$ & $1-6 \%$ & $1-6 \%$ & $0-1 \%$ \\
$0,05-0,1$ & $1-3$ & $0-3$ & $0-1$ & $1-2$ & $1-2$ & 1 \\
$0,1-0,25$ & $3-8$ & $2-6$ & $0-1$ & $10-20$ & $2-12$ & $2-3$ \\
$0,25-0,50$ & $35-56$ & $13-30$ & $1-3$ & $50-70$ & $15-30$ & $17-20$ \\
$0,50-0,75$ & $20-28$ & $40-60$ & $20-30$ & $10-35$ & $40-55$ & $28-32$ \\
$0,75-1,00$ & $9-20$ & $14-25$ & $40-46$ & $5-15$ & $6-20$ & $30-36$ \\
$1,00-1,50$ & $2-4$ & $2-8$ & $6-20$ & $1-5$ & $1-3$ & $6-10$ \\
$1,50-2,00$ & $1-2$ & $1-3$ & $2-6$ & $0-1$ & $1-2$ & $3-5$ \\
& $0-1$ & $0-1$ & $0-2$ & $0-1$ & $0-1$ & $1-2$
\end{tabular}

Die Dünensande weisen weißliche, graue, ockerfarbige bis ockrigbraune Färbungen auf. Die heutigen Oberflächenformen der Dünensande sind in überwiegender Mehrheit durch die bestehenden Forstbestände gefestigt, so daß eine Fortbewegung nicht mehr erfolgt.

Im erforschten Gebiete sind am meisten die Dünensande der II. Kornvarietät verbreitet; jene der I. Kornvarietät sind weniger vertreten, während die III. Kornvarietät noch seltener vorgefunden wird.

Die Dünensande der II. Kornvarietät weisen, wie schon gesagt wurde, überwiegend die Kornfraktion von 0,25-0,50 mm Durchmesser auf, welche mengenmäßig mit 40-60\% vertreten ist. Die größten Körneranteile von $0,25-0,5 \mathrm{~mm}$ sind in den Dünensanden des Elberaums, die kleinsten dagegen im Gebiete des nordmährischen Beckens festgestellt. Die Dünensande dieser Körnungsvarietät sind sowohl im Bereiche Böhmens als auch in Mähren verbreitet.

Für die Körnigkeit der Sande der I. Kornvarietät ist das markante Übergewicht der Körnerfraktion $0,1-0,25 \mathrm{~mm}$, welche mit $35-56 \%$ vertreten ist, besonders bezeichnend. Die feinkörnigen Dünensande dieser Varietät I treten hauptsächlich im Gebiete Mährens auf und sind in ausgeprägtester Form in Südmähren und zwar im Bisenz-Gödinger Bereiche entwickelt.

Die Dünensande der III. Kornvarietät sind im wesentlichen die gröbsten des erforschten Gebietes und treten insbesondere durch ihre von $0,50-0,75 \mathrm{~mm}$ reichende Kornfraktion markant auf, welche mengenmäßig mit $40-46 \%$ vertreten ist. Im Sinne dieser Einteilung sind die Dünensande insbesondere in Ost- und Südböhmen entwickelt, in kleinerem Ausmaße bilden sie auch die Basalschichten der Dünensande in Südmähren.

Im ausgedehnten Bereiche der Dünensande in Südmähren bei Bzenec-Hodonín (BisenzGöding) wurde durch granulometrische Analysen festgestellt, daß in der Richtung vom Flusse Morava (March) gegen NW zu die Feinkörnigkeit der Sande zunimmt und umgekehrt in der Richtung auf diesen Fluß hin wieder die Grobkörnigkeit eine Steigerung aufweist. Est steht dies in engem Zusammenhange mit der Entstehung dieser Dünensande von den Pleistozänterrassen des Marchflusses her. Der Aufbau der Dünensande weist in der Regel eine abweichende Korngrößen-Zusammensetzung der einzelnen Schichten auf, was darauf hindeutet, daß diese Dünensande teils durch verschiedene Windintensität von verschiedener Tragkraft, teils in mehreren Phasen mit kürzeren Hiaten in der Sedimen- 
tation gebildet wurden. Es wird dies auch durch die mehr oder weniger deutliche Schichtung einiger Dünen sowie durch Zwischenschichten von begrabenen Böden bekräftigt. Einige der erforschten Profile weisen auch eine ausgeprägte Vergröberung der Korngröße in Richtung auf die unteren Schichten hin auf, was auch die enge genetische Beziehung zwischen den Dünensanden und den sandig-schotterigen Unterlagsterrassen dokumentiert.

Das Verhältnis der scharfkantigen und abgerundeten Körner kommt in der Regel dadurch zum Ausdruck, daß ihre Abrundung in den oberen Schichten meistens höher ist als jene in den tieferliegenden Basalschichten. In den oberen Sandschichten schwankt das Verhältnis der scharfkantigen zu den abgerundeten Körnern in einem Bereich zwischen $4: 6$ bis $2: 8$, in Untergrundschichten zwischen $5: 5$ bis $3: 7$. Die Einzelschichten der übereinander liegenden Sande weisen oft ziemlich große Unterschiede in ihrer Abrundung auf, was wiederum auf verschiene Phasen, bzw. Hiaten in der Bildung der Sande hindeutet. Gut abgerundet sind hauptsächlich die gröberen Sandkörner; umgekehrt sind die Fraktionen der Körner von kleineren Durchschnitten als $0,50 \mathrm{~mm}$ oder 0,25 mm überwiegend scharfkantig ohne deutlichere Abrundung.

In petrographischer Hinsicht sind die Dünensande neben den Tonteilchen aus Quarz, Feldspäten und anderen, hauptsächlich schweren, Mineralien gebildet (Tab. 2). Der Quarzgehalt beträgt 56-94\% . In der Richtung von unten nach oben wird der Quarzgehalt in der Regel höher. Die Feldspäte sind hier mit einer kleineren Menge vertreten und zwar durchschnittlich etwa zwischen $7-12 \%$. Von den Feldspäten sind die Orthoklase und Plagioklase vertreten, wobei die ersteren größtenteils überwiegen.

Tabelle 2

Petrographische Zusammensetzung der Dünensande im Gebiete der ČSSR.

\begin{tabular}{l|c|c}
\hline & Gebiet des Böhmischen Massivs & Karpatengebiet \\
\hline Quarz & $72-94 \%$ & $67-93 \%$ \\
Feldspäte & $3-16$ & $6-15$ \\
Mineralien mit spez. & $1-8$ & $2-6$ \\
Gewicht $>2,80$ & 0 & $3-16$ \\
Calcit & &
\end{tabular}

Die übrigen Mineralien (hauptsächlich die schweren) wurden, zwischen den Grenzwerten von 0,8 und $6,5 \%$ schwankend, durchschnittlich in einer Menge von $1-5 \%$ ermittelt. Es wurden hauptsächlich folgende Minerale festgestellt: Limonit, Haematit, Magnetit, Ilmenit, Rutil, Muskovit, Biotit, Serizit, Chlorit, Amphibol, Granat, Turmalin, Epidot, Zirkon, Titanit, Sillimanit, Aktinolith, Zoisit u. a. In einigen Sanden bestehen die Körner aus kleinen Gesteinsbruchstïcken (Gneis, Quarzit, Phyllit, Sandstein). Die petrographische Zusammensetzung der Dünensande stimmt meistens mit den sandigschotterigen Unterlags- oder umliegenden Pleistozänterrassen überein, von welchen sie ausgeweht wurden.

Die Oberflächenschichten der Dünensande sind von verschiedenem geologischen Alter, und stellenweise wurden z. B. selbst die älteren Sande im Laufe der jüngeren Perioden überweht und resedimentiert. Als die ältesten kann man die Dünensande auf der Pleistozännterrasse mit nordischem Material in der schlesischen Niederung bei Vidnava (Weidenau) ansehen; ihre Entstehung dürfte ungefähr in die erste Hälfte der Rißglazialperiode, eventuell gegen das Ende des Mindelglazials, gelegt werden. Die jüngeren Dünensande sind sodann mit ihrer Basis auf den Schotter-Terrassen oberhalb der Alluvialfluren der Flüsse Labe (Elbe), Orlice (Adler), Lužnice, Morava (March) und Thaya (Dyje) gelagert 
und weisen auf Alt- bis Mittelwürmalter hin. Die jüngsten Dünensande schließlich sind jene, welche mit ihrer Basis auf der Schotter-Terrasse unterhalb der Alluvialflur gelagert sind und deren oberen Dünenteile die Ebene der alluvialen Sedimente der Flüsse Morava (March) und Dyje (Thaya) überragen. Sie gehören in Würm 3 bis ins Postglazial. Im Flußgebiete der Labe (Elbe) sowie in Südmähren bei Věstonice (Unter-Wisternitz) wurde auf den Gipfeln der Dünensande Mesolithikum vorgefunden (von K. ŽE EERA), was für ihre bereits erwähnte Datierung von Bedeutung ist.

Die Ablagerungen der Dünensande unterhalb der Alluvialflur auf den sandig-schotterigen Terrassen der Flüsse Labe (Elbe), Lužnice, Morava (March) und Dyje (Thaya) und ihre teilweise Bedeckung mit Holozän-Flußsedimenten deuten auf ein ständiges Sinken dieses Geländes hin.

\section{Die Dünensandedes Karpathengebietes}

Die Dünensande sind in der Slowakei im Bereiche der Záhoří-Niederung und in der Südund Ostslowakei verbreitet. Sie bilden daselbst mächtige Bedeckungen in den Niederungslagen. In der Záhoří-Niederung findet man diese Dünensande in den Lagen von 150 bis $244 \mathrm{~m}$ ü.d.M. (zumeist $170-200 \mathrm{~m}$ ), in der Südslowakei im Donauraum in den Seehöhen von 110-133 m ï.d.M., am unteren Laufe der Flüsse Váh (Waag), Nitra (Neutra) und Hron (Gran) in den Seehöhen 110-135 $\mathrm{m}$ und in der Ostslowakei in den Seehöhen 100-105 m (ausnahmsweise 150-160 m). Die Dünensande im Bereiche der Slowakei schwanken also in ihrer Höhenlage zwischen 100 und $244 \mathrm{~m}$, wobei sich die höchstgelegenen im östlichen Teile der Záhoří-Niederung, die tiefstliegenden in der Ostslowakei vorfinden.

Die Relativhöhe der Dünen ist auch verschieden und schwankt in einer Grenzweite zwischen 2-30 m. Die Unterlage der Dünensande bilden hauptsächlich die sandig-schotterigen Pleistozänterrassen verschiedenen Alters, ferner die Lösse, die Holozänablagerungen und stellenweise auch die Neogensedimente. Im Bereiche der Alluvialebenen wurden die Dünensande in einer Tiefe von etwa $1-2 \mathrm{~m}$ unterhalb der Alluvialsedimente auf Schotterterrassen abgelagert.

Im Karpathenbereiche sind meistens die Dünensande der I. und II. Körnungsvarietät verbreitet, und nur wenig erscheinen die Dünensande der III. Körnungsvarietät.

Für die I. Korngrößenvarietät ist die Kornfraktion von 0,1-0,25 $\mathrm{mm}$ besonders bezeichnend, indem sie durchschnittlich mit einem Mengenanteil von 50-70\% vertreten ist. Von besonderem Interesse und für die Genesis zugleich sehr wichtig ist hier der Gehalt an Staubsand (Korngrößendurchmesser 0,05-0,1 mm), welcher in einigen Sanden am unteren Flußlauf der Flüsse Váh (Waag) und Nitra (Neutra) und in der Ostslowakei in einer Durchschnittsmenge von 10-20\% ermittelt wurde; stellenweise erreicht dieser Anteil sogar 30-34\%. Der hohe Gehalt an dieser Fraktion bezeugt, daß an der Bildung von solchen Dünensanden die sandigen Neogensedimente beteiligt waren, für welche der Gehalt an diesem Staubsande besonders bezeichnend ist.

In den Sanden der II. Korngrößenvarietät überwiegt die Körnerfraktion 0,1-0,25 mm mit $15-30 \%$ und die Körnerfraktion $0,50-0,75 \mathrm{~mm}$ mit einem Anteil von $6-20 \%$. In den Dünensanden der Ostslowakei erscheint wieder eine erhöhte Menge von Staubsand, durchschnittlich 10-15\%, welche auf den genetischen Zusammenhang mit sandigen Neogensedimenten hindeutet.

Die Dünensande der III. Körnungsvarietät sind im wesentlichen die gröbsten Sande des untersuchten Bereiches und sind besonders durch die Kornfraktion 0,50-0.75 mm markant. Die Dünensande von dieser gröberen Körnungszusammensetzung bilden nur im Donauraum einige der Basalschichten, welche auf den Pleistozänterrassen gelagert sind. 
Im ausgedehnten Bereiche der Dünensande in der Záhoř́í-Niederung wurde durch granulometrische Analysen festgestellt, daß in der Richtung vom Flusse Morava (March) ostwärts die Feinkörnigkeit dieser Dünensande zunimmt. Es steht dies augenscheinlich in engem Zusammenhange mit der Genesis dieser Sande, welche aus den Pleistozänterrassen des Flusses Morava (March) ausgeweht wurden.

Der Aufbau der Dünensande weist in der Regel eine mehr oder weniger abweichende Körnungszusammensetzung der Einzelschichten auf, was darauf hindeutet, daß diese Dünensande teils durch verschiedene Windintensität mit verschiedener Tragkraft, teils in mehreren Phasen mit kürzeren Hiaten gebildet wurden. Dies wird auch durch die mehr oder weniger deutliche Schichtung einiger Dünen sowie durch das Vorkommen der sog. begrabenen Böden bestätigt.

Einige der untersuchten Profile weisen auch eine von oben nach unten zunehmende Vergröberung der Korngröße auf, was wiederum den engen genetischen Zusammenhang zwischen den Dünensanden einerseits und den sandigschotterigen Terrassen, auf denen sie liegen, bezeugt (Záhoří-Niederung, die Zone des eigentlichen Donauraums).

Die Abrundung der Körner ist in den oberen Schichten gewöhnlich höher als in den Basalschichten. In den oberen Sandschichten liegt das Verhältnis der scharfkantigen zu den abgerundeten Körnern zwischen den Grenzwerten 4:6 bis 1:9, in Untergrundschichten zwischen 7:3 bis 1:9. Starkes Übergewicht der abgerundeten und mehr ovalen Körner kommt bei den Dünensanden der Záhoří-Niederung vor, während die süd- und ostslowakischen Dünensande oft ein Übergewicht der scharfkantigen über die abgerundeten Körnern aufweisen. Dies deutet auf einen verschieden langen Transport des äolischen Materials hin.

Die einzelnen Schichten der höheren Sandpartien weichen in ihrer Abrundung ziemlich voneinander $a b$, was wiederum auf die verschiedenen Phasen bzw. Hiaten in der Bildung dieser Sande hindeutet. Gut abgerundet sind hauptsächlich die größeren Sandkörner; umgekehrt sind die Korn-Fraktionen von einem Durchmesser unter 0,50 oder 0,25 mm bereits überwiegend scharfkantig.

In petrographischer Hinsicht werden die Dünensande neben den tonigen Quarzteilchen aus Feldspäten, Calcit und sonstigen (hauptsächlich schweren) Mineralen gebildet. Der Quarzgehalt wurde $z$ wischen $65-93 \%$, durchschnittlich etwa zwischen $65-85 \%$, vorgefunden. Die Feldspäte sind mit einer kleineren Menge vertreten, und ihr Gehalt schwankt zwischen 6 und $15^{\circ} \%$, durchschnittlich etwa zwischen 7 und $11 \%$.

Der Calcit (0-16\%) erscheint in den kalkhaltigen Dünensanden der Süd- und Ostslowakei in Form von Körnern oder rhomboedrischen Kristallchen. Gegen die Oberflächenschichten zu nimmt sein Gehalt ab, stellenweise fehlt er überhaupt.

Die sonstigen Minerale (hauptsächlich die schweren) wurden in einer Menge zwischen 1 und $8 \%$, durchschnittlich $2-4 \%$ ermittelt. In den oberen Sandschichten sind diese Minerale weniger enthalten als im Untergrunde. Es wurden hauptsächlich folgende $\mathrm{Mi}$ nerale festgestellt: Limonit, Haematit, Magnetit, Ilmenit, Rutil, Muskovit, Biotit, Chlorit, Amphibol, Augit, Granat, Turmalin, Epidot, Zirkon, Titanit, Aktinolith u. a. In einigen Sanden sind die Körner aus kleinen Gesteinsbruchstücken gebildet.

Das Calciumkarbonat $\mathrm{CaCO}_{3}$ ist in den kalkhaltigen Dünensanden der Süd- und Ostslowakei in einer Menge von 10-16\% enthalten; dieser Gehalt sinkt in den oberen Schichten bis auf $2-7 \%$ und ist aus diesen stellenweise fast vollkommen ausgeschwemmt, wie dies z. B. in den Dünensanden der Ostslowakei der Fall ist.

Als jünger kann man hier die Dünensande beurteilen, die auf der schotterigen Terrasse unterhalb der Alluvialebene gelagert liegen; diese Ebene besteht aus lehmigen bis tonigen pelitischen Holozänsedimenten, so daß nur ein Teil der Dünen die umliegende Alluvial- 
flur übersteigt. Es sind dies die Dünensande vom Würm 3- bis Postglazialalter, und einige von ihnen wurden selbst noch im Holozän überweht, so daß auf der Alluvialflur noch sekundäre, ihrem Wesen nach die jüngsten Dünen gebildet wurden.

Die älteren Dünensande bedecken die schotterigen, bereits oberhalb der Alluvialflur gelegenen Pleistozänterrassen oder aber die höher abgelagerten Neogensedimente oder Andesite. Diese älteren Sande enthalten verschiedene periglaziale Erscheinungen wie z. B. Würge-Böden, limonitische Involutionsschichten, und man kann sie als würm-zeitlich, evtl. auch als riß-zeitlich datieren.

Die Dünensande der Záhoří-Niederung und der Südslowakei sind überwiegend durch die Wirkung von W- und N-Winden entstanden; an der Bildung der Dünensande der Ostslowakei haben hauptsächlich die Winde der S- und SO-Richtungen mitgewirkt.

Die Ablagerung der Dünensande mit Basen unterhalb der Alluvialflur, auf den sandigschotterigen Terrassen des Morava-Flusses (March), der Donau, des unteren Váh-Laufes (Waag), der Nitra (Neutra) und der Latorica, und ihre teilweise Bedeckung durch holozäne Flußsedimente deutet ein ständiges Sinken dieser Gelände an.

Die Dünensande der untersuchten ČSSR-Gebiete wurden überwiegend durch Winde mit einer Geschwindigkeit von 3-9 m/sec. transportiert, während die Winde größerer Intensität dabei weniger mitgewirkt haben. Erhöhte Schwankungen der Windintensität bei der Bildung der Dünensande sind im Bereiche der Záhoří-Niederung und in der Südslowakei ersichtlich; kleinere Änderungen der Windintensität waren im Bereiche der Ostslowakei, südlich des Latorica-Flusses, mitwirkend.

\section{Liter a tur:}

Barta, J.: Pleistocénne piesečné duny pri Seredi a ich paleolitické a mezolitické osídlenie. - Slovenská Archeologia, 5, Praha 1957.

DEMEK, Jar.: Složení vátých a terasových písků z východního okolí Pardubic. - Sborník československé společnosti zeměpisné, 3, 1958.

Dlabač, M.; Pr.čć, M.: Příspěvek ku geologii vátých písků mezi Rohatcem a železniční stanicí Strážnice. - Př́voz - Sborník ústředního ústavu geologického, Praha 1958.

HRUŠKA, B.: Př́íspěvek k charakteristice přesypových písků hornomoravského úvalu. - Antropozoikum, 5, Praha 1955.

СнÁbera, S.: Pískové přesypy v jižních Čechách. - Vesmír, Praha 1953.

JANŠÁK, Št.: Eolické formacie na Slovensku. - Slovenská Akademia vied, Bratislava 1950.

Krejčí, J.: Přesypy u Plané nad Lužnicí. - Sborník československé společnosti zeměpisné, 32, Praha 1936. - - Zajímavé tvary detailní modelace v přsesypových píscích. - Sborník české společnosti zeměpisné, Praha 1943.

LuKNIŠ, M. a BučKo, Št.: Geomorfologické poměry Podunajskej nížiny v oblasti medzi Novými Zámkami a Komárnem. - Geografický časopis Slovenské Akademie vied, 5, 1953.

LukNiš, M. a Mazur, E.: Geomorfologické regiony Žitného ostrova. - Geografický časopis Slovenské Akademie vied, 11, č. 3, 1959.

PeLíšEk, J.: Charakteristika přesypových písků kvartéru Československé republiky. - Anthropozoikum, 5, Praha 1955. - - Pŕesypové písky jižní Moravy. - Př́ŕroda, 42, č. 1, Praha 1949. - - Písčité půdy jižní Moravy. - Sborník prací "Hospodaření vodou v našich nejsušších oblastech“, Praha 1947. - - Pískové přesypy v okolí Hodonína. - Práce Moravské přírodověcké společnosti, Brno 1943.

Půrkyně, C.: Přesypy u Živanic mezi Bohdančí a Přeloučí. - Věda př́rodní 1920.

SEKyra, J.: Kvartér severozápadního výběžku Železných hor. - Anthropozoikum, 6, 1956. - Zpráva o pedogeologickém mapování na listu Chrudim. - Věstník ústředního Ustavu geologického Praha 1952.

Schwarz, R.: Vysvětlivky k přehledné mapě základových půd list Hodonín 4458 (r. 1950). - Zpráva o půdoznaleckém výzkumu na listu Hodonín, Praha 1947. 
SíibraVA, Vlad.: Výzkum vátých písků. Zprávy o geologickych výzkumech v roce 1959. - Ústředni ústav geologicky, Praha 1961.

Š́tAhor, Lud.: Poznámky k pokryvným útvarom okolí Král. Chlmca. - Geologický sborník, 6, č. 1-2, Bratislava 1955.

UrbáNEK, L.: Aeolické sedimenty katastru kolínského. - Sborník Ústředního ústavu geologického, Praha 1949.

VITÁsex, Frant.: Pískové přesypy na dolní Moravě. - Sborník prací III. sjezdu československých geografi̊ v Plzni, 1935. - - Dolnomoravské přesypy. - Práce Moravské přírodovědecké společnosti, Brno 1942.

Žrbera, K.: Stář́i přesypů a navátých písků ve středočeském Polabí. - Anthropozoikum, 5, Praha 1955. - - Pluviální štěrkopísky na území speciální mapy listu Hradec Králové Pardubice. - Anthropozoikum, 5, Praha 1955. - - Základová půda velkých Pardubic. Anthropozoikum, 6, Praha 1956. - - Českos'ovensko ve starší době kamenné. - Praha 1958.

Anschrift des Verf.: Prof. Dr. Ing. Jos. Pelíšek, Institut für Geo'ogie und Bodenkunde, Brno, Zemědělská 3 , ČSSR. 